\title{
Anthropology and war - not only narrative
}

\section{Introduction}

The Graduate Program in Social Anthropology (PPGAS) of the National Museum of the Federal University of Rio de Janeiro, my original institution, will complete 50 years in 2018. It was the first PPGAS created after the so-called Sucupira Report, with which the new graduate studies format was inaugurated in Brazil in the second half of the 1960s. But this did not come out of nowhere and I would like on this occasion to record the importance of the University of São Paulo (USP) for us through the mention of some people: Ruth Cardoso (who supervised Gilberto Velho, Lígia Sigaud and Giralda Seyferth) and Eunice Durham. Not to mention Florestan Fernandes, who supervised some of the initial staff of our PPGAS: Roberto Cardoso de Oliveira, our founder; Francisca Isabel Schurig Vieira, later Koeller, who gives name to our library and Roque de Barros Laraia. And Luiz Pereira, a visiting professor in the heroic beginnings and who formally replaced Florestan as Roque Laraia`s supervisor when Florestan was expelled from the the University by the military regime (1964-85), as he did in many other cases. But this is also about a continuing relationship beyond the early days, other former students of our's coming to USP for their doctorate or being incorporated as faculty over the years.

Much more could be said about the relations between USP and the National Museum in our area, for example, more remotely, the presence of Luiz de Castro Faria in the Lévi-Strauss expedition. But today my institutional situation is different: I have been retired for more than ten years. Thus I lost contact with the institutional dayto-day. To some extent on purpose: I am just an Emeritus. This gives me another perspective, although the historical relationship does not fade away: first graduated student, first formal graduate student of our founder, etc. I am not doing field work anymore either. One of the consequences of this is being almost forced to speak about the past. Eyewitness of history, as a well-known and long gone radio news program would say. I have already written somewhat about this. For example when comparing the graduate studies of the 1970s with those of today including oral testimonies, in interviews; or in statements (not only mine) in events such as the "decelebration" of the 1964 civil-military coup and its extensions (I believe this testimony is available on the website). This is not without some productivity. For example, starting from the recognition (which should be obvious) that much of our institution's life spread took place in the context of an authoritarian regime. Not by chance, my doctoral thesis had to do with this, thus unfortunately gaining today an unexpected actuality, this revisiting almost corroborating at times theoretical positions put forward years ago. As also gains actuality due to our present political situation the question of how institution building was then practiced.

What was the price to pay? How were our relations with the regime? Relations of people who as in my case had left the country not only for academic reasons and had responded to a lawsuit in a Military Court, in illustrious company (and I mention this just to help visualize those supposedly distant times). This was all much more complicated than our vain philosophy supposes. In fact, just as in the 1970s I and others used the 1930s to understand comparatively what was happening, today we may actually have to resort to those same 1970s, as did the political scientist Helgio Trindade, who has just
Volume I Issue 3 - 2017

Otávio Velho
Federal University of Rio de Janeiro, Brazil

Correspondence: Otávio Velho, Federal University of Rio de Janeiro, Brazil, Email otaviogvelho@gmail.com

Received: June 23, 2017| Published: June 26, 2017

released a new book about the political movement called Integralism, a theme he explored in those days, forty years ago. And it should be noted that the references musical, pictorial and others of the popular or militant manifestations that are occurring a little everywhere these days seem to precede us. Hence the actuality of this madeleine of a search in the past, involving all the senses. A search that may even end up in an experience of collective anamnesis and a certain timelessness, even if fleeting: an antidote or panacea for any form of ungoverned developmentalism.

But beyond these considerations made from the past, so to speak, I believe there are others to which my present situation may at least allow for certain special emphases, not disconnected from the previous ones. And about that I'd like to talk a little. I would like to clarify, for instance, that in recent years I have deepened my relationship with the Brazilian scientific community, beyond anthropology and even the social sciences. The main instrument for this was the SBPC (Brazilian Society for the Advancement of Science), where I served two terms as vice president and ended up becoming one of its presidents of honor, the only one from the social sciences. But so was the participation in several boards associated to the so-called scientific policy and the entrance in the Brazilian Academy of Sciences. In this way, I was able to practice a kind of observant participation that gave me a better overview of the Brazilian scientific community, in which the presence of social scientists is generally somewhat peripheral and in my opinion more by self-exclusion than by any other reason. I have made remarks about our "inhuman" colleagues, as they call themselves ironically, apart from their internal differentiations. For example their missionary spirit as a product of an extraordinary belief in Science (with an emphasis on the capital S), which is very stimulating for someone like me, who has an interest in the relations between science and religion, albeit on a more epistemological level. A missionary spirit that makes them paradoxically more active than the so called social scientists in what concerns to practical actions concerning education in the country, such actions, however, being heavily laden with a triumphalist enlightenment ethos, which on the other hand leads them to cultivate a certain democratic spirit (which perhaps contrasts with some aristocratic and/or skeptical ethos of human scientists), on the assumption that only unrestricted enlargement of the recruitment base will enable sustainable scientific development. A democratic spirit that is also paradoxical, inasmuch as the greater value remains ultimately based on Science and not on social values. What is admirable and even enviable is the possibility of transcending the horizon of the here and now, similarly to what the religious traditions propose. This also being difficult to capture by skeptics, who only see utilitarianism and co-optation by the State where sometimes what is hidden is a greater 
determination from the part of scientists and their organizations to put to the service of their interests both God and the Devil, without prejudice or restraint. This sometimes resulting in that their political stances become surprising when viewed from the customary political optics or dominant social values. As, for example, when the President of the SBPC (and remember what the acronym stands for: Brazilian Society for the Advancement of Science) suggests that in the present circumstances the best young scientists can do is to leave the country, thus expressing a version of scientific universalism somewhat shocking for us.

On the other hand, it has also interested me to reflect by contrast on the nature of the current commitment of the anthropologists with our society, here also beyond our differentiations. A commitment where it may be reasonable to assume that the "nation-building", which in my generation we identify with the pioneering work of Mariza Peirano is still present, even if subject to criticism or transformation. A commitment that in this same generation, in its substance, is associated with a culturalism, possibly better personified by Roberto da Matta, that on the one hand, directly or indirectly influenced all of us anthropologists and social scientists in general (Luiz Jorge Werneck Vianna some years ago noticed that Matta was found to be the most recurrent reference in the bibliographies of our courses) and on the other hand, Matta far surpassed the boundaries of the discipline, making himself a kind of celebrity.

Having made that observation, however, what would be the situation today? How do we procede from here? And I emphasize that my observations are from a particular perspective, which is not intended to encompass everything. The first point to highlight is perhaps that we have now lost mastery over our own concepts, starting with culture and its complex. And that our first reaction purist before this is no longer sustainable, given the strength and comprehensiveness of the phenomenon. The second reaction of flight to the front by the rejection of those same concepts in the face of its vulgarization also does not seem to find sufficient echo. The much exaggerated social constructionism that usually fuels this reaction seems to find its limit. This is due on the one hand to the general revival of ontological concerns, now tempered by a certain anti-dogmatic element and including among anthropologists, for example a renewed and nonobjectifying look at animism and on the other hand, in the face of the reappropriation of culturalism by our own privileged interlocutors (our former "informants"), in a kind of essencialist compensatory resistance - an ironic twist that somehow ends up by affecting us.

Our privileged interlocutors will be presupposed in what I will be talking about next. But it is worth mentioning in what respects to the revival of ontological concerns, as they are a symptom of how our intellectual field works, that these concerns arise in a seemingly independent way in several places between which there is sometimes little communication. This lack of communication being however, possibly also a symptom of an indirect interdependence, the fruit of an unrecognized encompassing spirit of the times. A spirit which can be termed ecological if we do not restrict the expression to the socalled environment. Only recently, for example did I learn through Ypuan Garcia (who defended a thesis at USP under the supervision of Paula Montero) about the focus of an object oriented ontology that dates back to the 1990s and which had already systematized concerns that were also present in the work of various anthropologists (among whom I would include myself, along with other supposed "specialists" in religion), but that would only become a subject of a specific discussion among us later, its previous presence in other contexts not always being recognized.

But returning to the question about the situation today, I would like to set another tone here. This is due to the impact of the publication of a recent Parlimentary Comission Enquiry`s final report dealing with the issue of indian lands, which together with indigenous people, quilombolas, rural settlers, activists, missionaries and prosecutors, also affects more than twenty anthropologists and cites in an accusing way the Brazilian Association of Anthropology itself. It is difficult to ignore the reality of this document which, moreover, seems to me to have to do albeit in an extremely surprising and unusual way with what we are developing here. For it throws us in a brutal manner that does not correspond to the usual image of our academic practice, in the matter posed earlier of the nature of the current commitment of anthropologists to our society. Exactly us, who sometimes seemed distant from the democratic spirit of the "inhuman" scientists, revealed in their preoccupations with education. It is therefore very hesitantly that I proceed; a confession that retirees might be able to make more easily than their younger colleagues, assuming a kind of slow anthropology that does not have much to do with the current deadlines of funding agencies and university standards. But that's another story. What I mean is that such a report with all its nonsense, inconsistencies and malice, just as Nebuchadnezzar in the role of God's servant helps us to see ourselves from the outside, in a way we might not have been able to do for ourselves. And what is revealed is our role in the war not only of narratives disputed by what was often termed in a somewhat detached non-ontological way, "interpretations of Brazil." This current role is a reversal of what we have represented in the past. If we were present in the construction of an "interpretation" akin to the primacy of "national unity", we now occupy a position of deconstruction. A position associated with our own professional métier as it presents itself today and with the affections that it carries; in part as the product of a change that is generational and in scale, insertion and distribution in space of the anthropologists. And that transposed to the field of politics seems to imply, certainly not the substitution of the classic opposition between Left and Right, but the recognition that it is not enough; just as the false alternative of contesting for a purity trophy on a Left-Right gradient is not enough. Within the Left, this brings to light a duality that has not yet defined its course, several of our neighboring countries presenting the exacerbation of severe opposition or even the emergence of an equidistant "third position," which can anticipate our future in an unpleasant way, if other arrangements are not made in time. It remains for us to bet, not on a conciliation as an alternative, but on the contrary, on a change in the terms of the debate, so that really vivified by ecology in a sense that incorporates virtualities to what is actual, permits us to think about the constitution of a new paradigm and not only in a conflict of positions or in a deconstruction that is exhausted in itself. This means knowing how to distinguish between this constitution as a long-term project and the politics of the here and now where we will also have to recognize our status as protagonists. A recognition that allows us to expand spaces and find the way to the constitution of this paradigm in the gaps of an inclusive civilizing project so that it does not become mere chimera. A project - itself, in its turn, still to be fully elaborated opposed to the forces of a new barbarism transvestited as an impoverished developmentalism now dominant in various clothing so that it can valorize and expand without repression exemplary local actions. The unprecedented technological advance we are witnessing nowadays makes this possibility unexpectedly present. This is not at 
all an archaic possibility, in a world in which work, as it has been constituted in the various industrial revolutions, seems to tend to undo itself, to the horror of those still clinging to this old paradigm and its values (among which are understandably included their own victims), not seeing the possibilities that can open up with this breakdown. It can lead to a world of horrors, but it can also become akin to much that has until today been circumscribed to utopias.

All this however demands political action so that this latter path can become effective. And it does not depend only on us, but also on the disposition of our eventual allies, who tend to stubbornly regard our demands as merely sectoral and subordinate and not as another way of being in the world, they themselves being very resistant to the recognition of this need. A need that supposes the abandonment, in all planes of an exacerbated Eurocentric posture, more realistic than that of the king as a Brazilian saying goes, thus raising with it significant self-restraint and qualification on the part of the developmental model, passing through a thorough reassessment of its heteronymous objectives in its retrospective mimicry. Self-restraint and qualification forced by the presence and legitimacy of other logics, of an ecological bias in its widest sense and of the primacy of the search for the wellbeing of the people in their diversity. The State then, would only merit recognition in its turn, while in the face of the free market forces it can be used as the democratic instrument par excellence of this policy for which no substitute has yet been found. And not serving as an end in itself and of a supposed national greatness that has not gone through ample discussion; or as a place of gestation for authoritarian practices, bureaucratic castes or simple collusion with unconfessable interests. The accompaniment of the policy directed towards the indians and its executing agency can be an exemplary case to test the vicissitudes of this two-fronted figure of the State. Not only because of the vulnerability of indigenous populations, but because of other difficulties, the incorporation of diversity as a value being a particularly difficult exercise for a society that although not as exceptional as we once imagined it is nourished on authoritarianism, slavery and coloniality. A very painful exercise indeed until one reaches the threshold beyond which perception transforms itself and one arrives at the level of singularities, like in our ethnographic objects. This being also a test for all the actors involved that do not seek to instrumentalize the various groups and social movements projecting a face that does not correspond to them in order to charge them with responsibilities corresponding to that construction. On the contrary, one should recognize their right to speak for themselves, making room for an authentic participatory process at all levels and that goes beyond a simple sum of illusory free individuals.

We must, for all of this and beyond divergences, rely on the clairvoyance of thinkers such as Immanuel Wallerstein, that in a recent text ("Global Left vs. Global Right: From 1945 to Today", Commentary No. 449, May 15, 2017) says: "If the Global Left is to win that battle (the battle for the system that will succeed capitalism), it must solidly ally the anti-austerity forces with the multicultural forces."

This means that the issue is about building a transition with audacity, but also without sectarianism, respecting the different tempos and recognizing our own inadequacies and incompleteness, without pretending that we have all the answers. It is how I personally feel, although recognizing that the task is difficult and subject to misunderstandings, divergences, clashes of all kinds and the sometimes complicated exercise of dialogue and politics in its best sense, which needs to be taken up and revalued. For I think it will be necessary, for example, to refine what would be the alternative to so-called austerity, so that we do not restrict ourselves to a poor economicist and consumerist vision, incapable of generating a new paradigm. It being also necessary to revise the very notion of multiculturalism, too bound to the presupposition of a limited and tensionless totality.

But I also believe that the revaluation of politics, understood as associated with experience, imagination and sensibility can even on our own anthropological terrain, teach us not to be frozen by any concepts and not to turn them into battle horses in an insane intellectualist discussion. Not because of the autonomy of the language games, but precisely because the identification of the real with language is again questioned, at the same time as the restriction of the real to the present and the actual. And above all, I also believe that despite the regrets this is a task with which a good part of anthropologists can find significant affinity and a sense of life. Even in the development of a non-anthropocentric anthropology, in the heat of social conflicts. Conflicts which should not be seen as a mere field for the eventual exercise of university extension, since life has taught us that, even when they are not the object of study, conflicts may surprise us at any moment in the very exercise of professional and academic activity, such as this activity has come to be configured objectively in its dynamics. A dynamic that in turn should not be seen as primarily endogenous. If this is already being learned even by our "inhumane" colleagues, provoking unusual reactions like the recent widespread Marches in Defense of Science, what about us?

These at least are questions that express how I see the world through the eyes of a retiree. And who knows if they may not help to demonstrate that we are not only a hindrance to public finances? But as the poet Manoel de Barros says:

"I only use words to make up my silences."

\section{Acknowledgements}

None.

\section{Conflict of interest}

Author declares there is no conflict of interest in publishing the article. 